Bull. Mater. Sa., Vol. 19, Vo. 1. Februay 1996, pp. 41 102. 1 Prnted an Inda.

\title{
Role of surface passive films in the hydrogen embrittlement of iron aluminides
}

\begin{abstract}
ARVIND AGARWAL and R BALASUBRAMANIAM
Department of Materials and Metallurgical Engineering, Indian Institute of Technology, Kanpur 208016, India

Ihstract. The room temperature hydrogen embrittlement problem in iron aluminides has restricted their use as high temperature structural materials. Previous studies have established that surface films affect hydrogen embrittlement (HE). The effect of surface passive ayer on the hydrogen embrittlement behaviour of iron aluminides has been critically reviewed in this presentation. The role of thermomechanical treatments in affecting the mechanical properties has been discussed from a processing-structure-properties correlation view point. The alloy development philosophy to yield ductile iron aluminides has been outlined based on this ruview. Novel iron aluminide intermetallics that are being currently synthesized and characterized along these lines at IIT Kanpur are finally introduced.
\end{abstract}

heywords. Structural intermetallics; iron aluminides; hydrogen embrittlement; decohesion; nassivity; structure-property-processing correlation.

\section{Introduction}

Ordered iron aluminide intermetallics of composition $\mathrm{Fe}_{3} \mathrm{Al}$ and $\mathrm{FeAl}$ possess attractive properties for application as structural materials at elevated temperature in aggressive environments. However, their poor room temperature ductility limits their lise as engineering materials as they are difficult to process into useful shapes like plates and tubes. In recent years. efforts have been intensified to identify both the extrinsic and intrinsic factors governing room temperature brittle fracture.

Several studies have established that the poor room temperature ductility is due to HE. The environmental degradation of iron aluminides has been critically reviewed, recently (Stoloff and Duquette 1993). Methods have also been proposed to minimize the problem. Most of the methods that have been suggested to curb HE aim to restrict entry of hydrogen into the lattice by providing an oxide film coating on the iron aluminides (McKamey and Liu 1990). Oxide coatings have been beneficial in increasing the ductility of iron aluminides. However. detailed oxidation studies of iron aluminides coupled with HE studies have not yet been conducted to elucidate the exact role played by the surface coatings on embrittlement. Another method for improving ductilities of ron aluminides is by the addition of chromium. Even small chromium additions are effective in minimizing hydrogen embrittlement and in providing increased ductilities (McKamey et al 1988). However, the role of chromium in affecting hydrogen embrittlement and in causing ductility enhancements is still unresolved. In this paper, the role of surface passive films in affecting the HE behaviour of iron aluminides is reviewed. An alloy development methodology to yield ductile iron aluminides is outlined.

\section{Iron aluminides}

Ordered intermetallics which form long range ordered crystal structures below their critical ordering temperatures constitute an emerging important class of metallic 
materials for high temperature structural applications. Iron aluminides are one of these important ordered intermetallic materials possessing advantages of excellent oxidation/high temperature corrosion resistance, low cost, relatively low density and by the conservation of strategic materials such as chromium.

Ordered iron aluminides exist in relatively narrow compositional ranges around simple stoichiometric ratios (figure 1). Table 1 presents some typical room temperature properties and critical ordering temperatures for different allotropic modifications of iron aluminides (Liu and Kumar 1993). Iron aluminides based on $\mathrm{Fe}_{3} \mathrm{Al}$ and $\mathrm{FeAl}$ can exist in two crystal allotropic modifications. These structures $\left(\mathrm{DO}_{3}\right.$ and $\left.\mathrm{B} 2\right)$ are both ordered $\mathrm{BCC}$ structures and these are presented in figure 2. Note that $\mathrm{Fe}_{3} \mathrm{Al}$ can exist

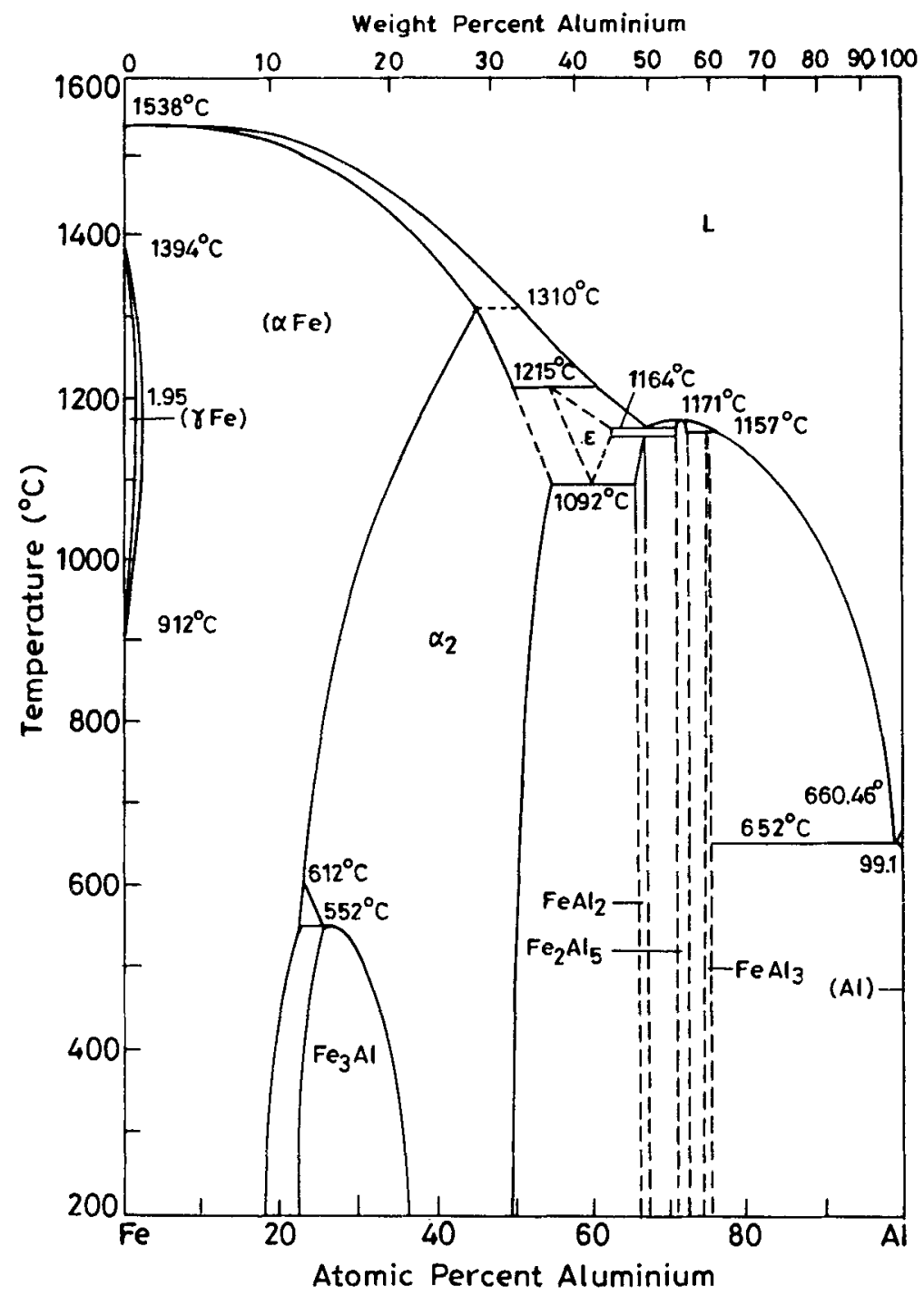

Figure 1. The $\mathrm{Fe}-\mathrm{Al}$ phase diagram. 
Surface films and HE oj iron aluminides

lable 1. Typical room temperature properties of iron alumndes.

\begin{tabular}{|c|c|c|c|c|c|c|}
\hline tlloy & $\begin{array}{l}\text { Crystal } \\
\text { structure }\end{array}$ & $\begin{array}{c}\text { Critical } \\
\text { ordering } \\
\text { temperature } \\
(\mathrm{C})\end{array}$ & $\begin{array}{l}\text { Melting } \\
\text { point }(\mathrm{C})\end{array}$ & $\begin{array}{l}\text { Density } \\
(\mathrm{gm} / \mathrm{cc})\end{array}$ & $\begin{array}{c}\text { Room } \\
\text { temperature } \\
\text { yield strength } \\
(\mathrm{MPa})\end{array}$ & $\begin{array}{c}\text { Room } \\
\text { temperature } \\
\text { elongation } \\
(\%)\end{array}$ \\
\hline $\mathrm{Fe}_{3} \mathrm{Al}$ & $\mathrm{DO}_{3}($ Ordered $\mathrm{BCC})$ & 540 & 1540 & 6.72 & 300 & 3.7 \\
\hline $\mathrm{He}_{3} \mathrm{Al}$ & B2 $($ Ordered BCC) & 760 & 1540 & 6.72 & 380 & $4 \cdot 1$ \\
\hline $\mathrm{FeAl}$ & $\mathrm{B} 2($ Ordered $\mathrm{BCC})$ & 1250 & 1250 & $5 \cdot 56$ & 360 & $2 \cdot 2$ \\
\hline
\end{tabular}

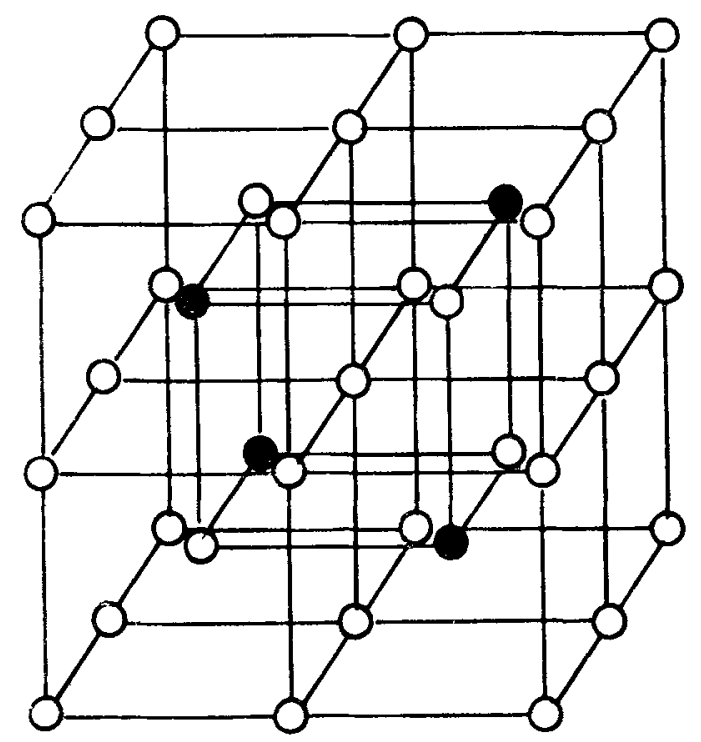

$\mathrm{Fe}_{3} \mathrm{Al}\left(\mathrm{DO}_{3}\right)$

O Fe Al

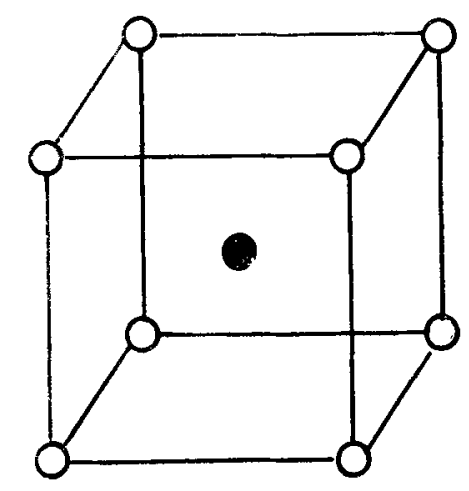

FeAl (B2)

Figure 2. The $\mathrm{DO}_{3}$ and $\mathrm{B} 2$ ordered crystal structures of iron aluminides. 
both as $\mathrm{B} 2$ and $\mathrm{DO}_{3}$ ordered structure (depending upon the temperature, see figure 1) while FeAl can exist only in the B2 ordered form (Liu and Kumar 1993).

\section{Hydrogen embrittlement of iron aluminides}

Iron aluminides exhibit poor ductilities at ambient temperature and environments. That hydrogen is the main damaging agent causing poor ductilities can be inferred from tensile tests conducted in different environments, the results of which are summarized in table 2 (Liu et al 1990). Testing in water vapour environments show the least ductility and vacuum/oxygen environments provide high ductilities.

Note that higher ductilities are observed in dry oxygen environment rather than in vacuum because oxygen reacts with aluminium to form $\mathrm{Al}_{2} \mathrm{O}_{3}$ directly

$$
2 \mathrm{Al}+3 / 2 \mathrm{O}_{2}=\mathrm{Al}_{2} \mathrm{O}_{3}
$$

and thereby suppressing the aluminium-moisture reaction providing nascent hydrogen

$$
2 \mathrm{Al}+3 \mathrm{H}_{2} \mathrm{O}=\mathrm{Al}_{2} \mathrm{O}_{3}+6 \mathrm{H} .
$$

Generation of atomic hydrogen is suppressed and higher ductilities are observed in dry oxygen environments. Therefore, by promoting the formation of an oxide layer on the surface it should be possible to minimize hydrogen entry into the lattice and limit the subsequent hydrogen embrittlement phenomenon. The effect of various test environments on the room temperature stress-strain behaviour of iron aluminides is summarized schematically in figure 3.

There is no unique mechanism which has been universally accepted to explain hydrogen embrittlement of iron aluminides. However, the process of HE in iron aluminides can be visualized as follows. The reaction that provides nascent hydrogen which embrittles iron aluminides is (2) above. The propensity of the above reaction

Table 2. Room temperature tensile properties of $\mathrm{Fe}_{3} \mathrm{Al}$ in different iest environments

\begin{tabular}{|c|c|c|c|}
\hline Environment & $\begin{array}{l}\text { Yield strength } \\
\text { (MPa) }\end{array}$ & $\begin{array}{l}\text { Ultimate tensile } \\
\text { strength (MPa) }\end{array}$ & $\begin{array}{c}\text { Ductility } \\
(\%)\end{array}$ \\
\hline \multicolumn{4}{|c|}{ Heat treated for $2 \mathrm{~h}$ at $700^{\circ} \mathrm{C}$ [B2 structure $]$} \\
\hline Vacuum & 387 & 851 & $12 \cdot 8$ \\
\hline Oxygen & 392 & 867 & $12 \cdot 0$ \\
\hline $\mathrm{Ar}+4 \% \mathrm{H}_{2}$ & 385 & 371 & $8 \cdot 4$ \\
\hline Air & 387 & 559 & $4 \cdot 1$ \\
\hline $\mathrm{H}_{2} \mathrm{O}$ vapour & 387 & 475 & $2 \cdot 1$ \\
\hline \multicolumn{4}{|c|}{ Heat treated for $120 \mathrm{~h}$ at $500^{\circ} \mathrm{C}\left[\mathrm{DO}_{3}\right.$ structure $]$} \\
\hline Vacuum & 316 & 813 & $12 \cdot 4$ \\
\hline Oxygen & 298 & 888 & $11 \cdot 7$ \\
\hline Air & 279 & 514 & $3 \cdot 7$ \\
\hline $\mathrm{H}_{2} \mathrm{O}$ vapour & .322 & 439 & $2 \cdot 1$ \\
\hline
\end{tabular}
(Liu et al 1990). 


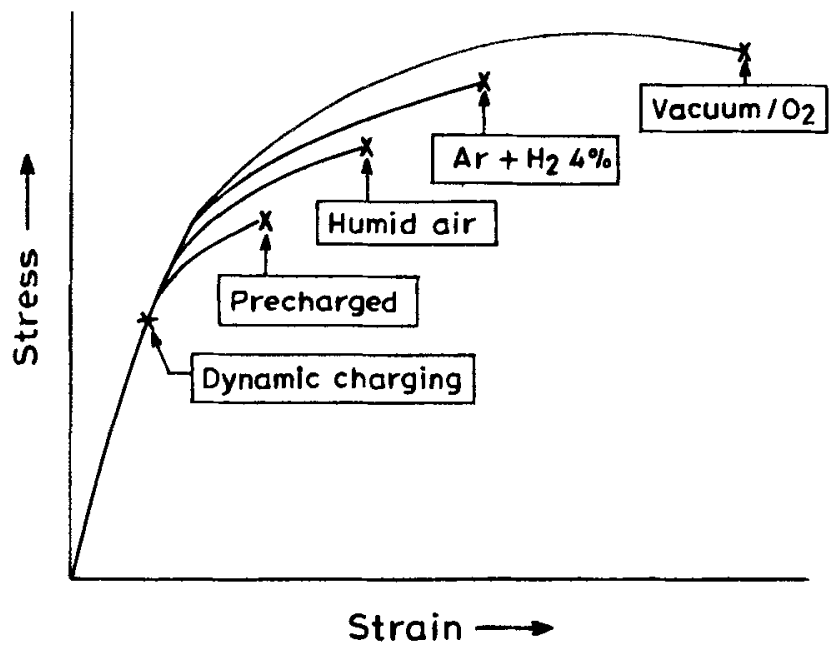

Figure 3. Schematic tensıle stress-strain behaviour of iron aluminides in various environments at ambient temperature.
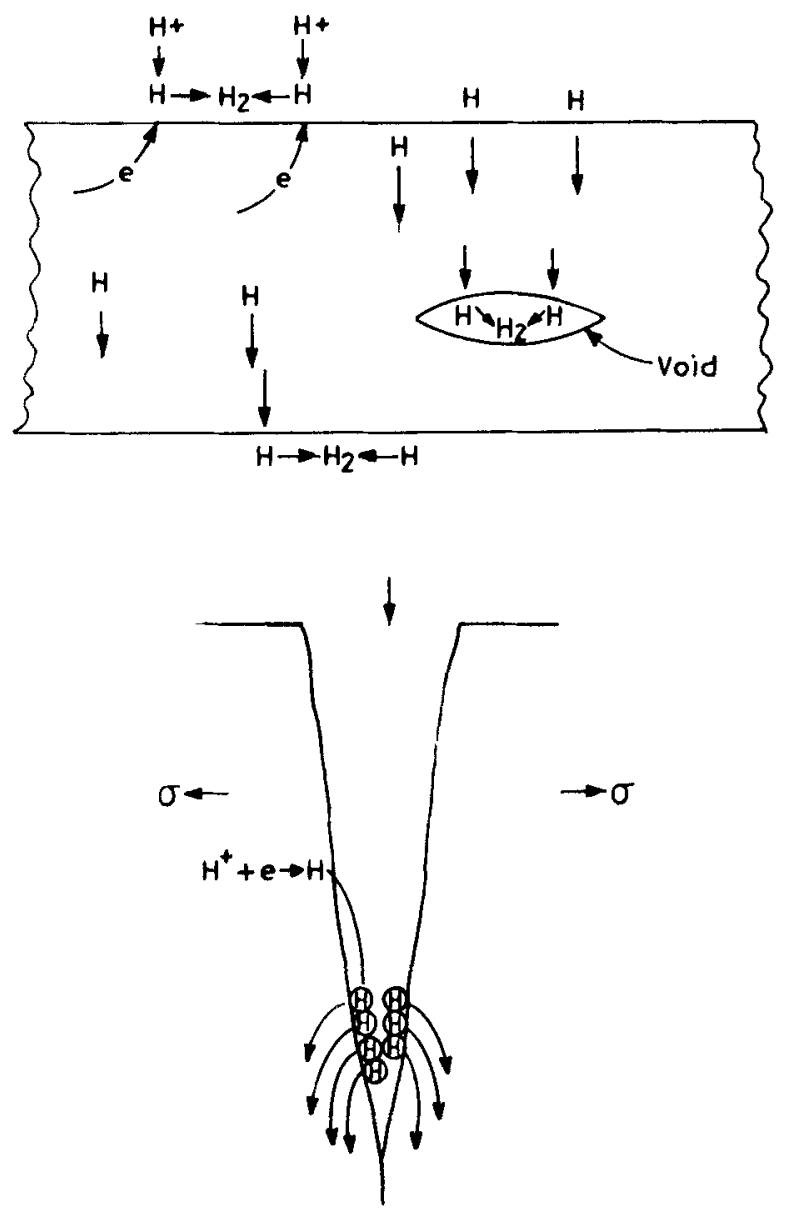

Figure 4. Hydrogen entry into the material and processes that occur at the crack tip during hydrogen embrittlement. 

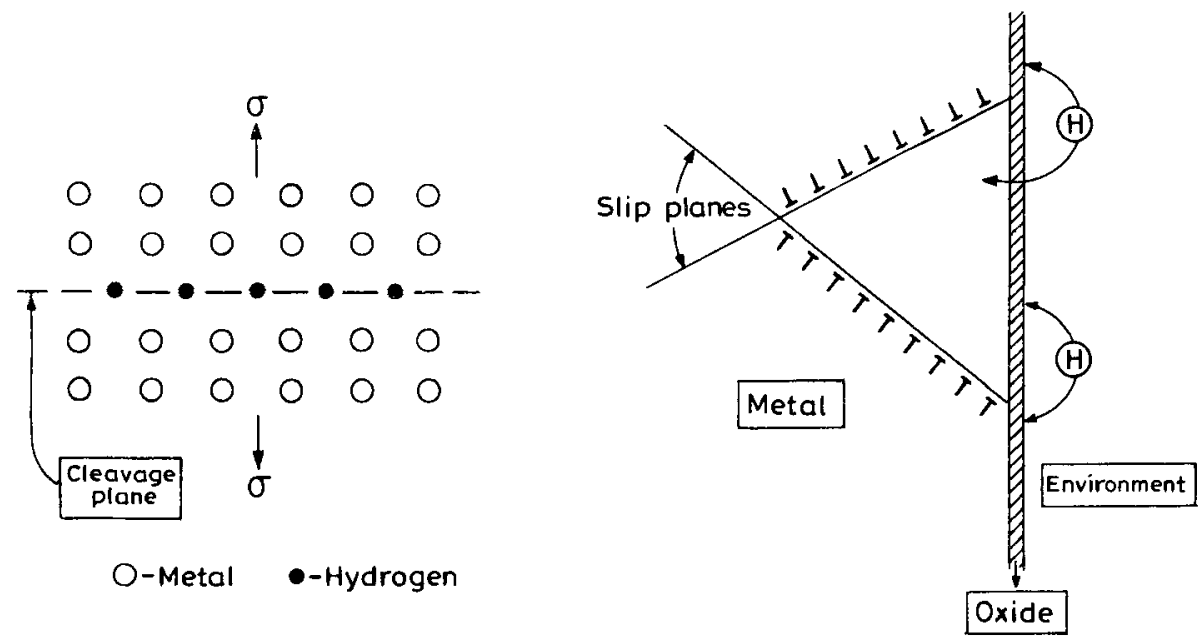

Figure 5. Hydrogen embrittlement mechanism by decohesion in tron aluminides.

increases with increasing aluminium concentrations. The reaction of condensed moisture from ambient environments with aluminium at crack tips and freshly created metal surfaces (due to oxide spallation) results in the generation of high fugacity atomic hydrogen that causes severe embrittlement. This process is schematically illustrated in figure 4.

Generally, the fracture appearance in these class of intermetallics is of cleavage type, with facets of $\{100\}$ type suggesting decohesion as the possible mechanism of hydrogen embrittlement. The decohesion mechanism of hydrogen embrittlement is shown in figure 5. Hydrogen enters the material after diffusion and adsorption on the surface. After this process, mobile dislocations trap hydrogen and carry it along with them to potential flaw sites. It is well known that dislocations in intermetallic structures are generally present in the form of partials. These partial dislocations glide on the $\{111\}$ type slip planes in the ordered $\mathrm{DO}_{3}$ and $\mathrm{B} 2$ structures and can be locked as immobile $\langle 100\rangle$ dislocations by the Lomer-Cotterel mechanism (Li and Liu 1992). Evidence for decohesion mechanism is based upon the brittle appearance of fracture surface (see figure 7) and the propensity for cleavage on $\{001\}$ planes in embrittled single crystals of intermetallic aluminides (Liu et al 1989). Moreover, the brittle appearance of hydrogen induced (or moisture induced) fatigue cracks in iron aluminide alloys also suggest decohesion as the likely mechanism of hydrogen embrittlement (Stoloff and Duquette 1993).

\section{Surface passive layer effect}

Of the several methods which have been adopted to minimize hydrogen embrittlement of iron aluminides, chromium additions have been very useful in increasing ductility by an order of magnitude (McKamey et al 1988). Table 3 summarizes the tensile behaviour of iron aluminides (McKamey et al 1988) where the effect of chromium additions can be observed. The exact mechanism for the increase in ductility by $\mathrm{Cr}$ 
addition is yet unresolved. A mechanism for the $\mathrm{Cr}$ alloying effect has been recently proposed and it is based on hydrogen reduction reaction rates on iron aluminide surfaces (Balasubramaniam 1996). Therefore, by manipulating surface conditions, entry of hydrogen into the lattice can be checked and HE minimized.

Corrosion characteristics can also be improved by surface conditioning. The effect of surface modifications on the hydrogen embrittlement behaviour of iron aluminides is briefly addressed below. The surface nature can be manipulated by several methods like electropolishing, oxide coating and alloying. The first two aspects were studied in detail by McKamey and Liu (1990). Tensile tests were carried out on iron aluminides having the following surface conditions: (a) electropolished surface (produced by first grinding to remove the as-received oxide and then electropolished), (b) as rolled condition consisting of a thin oxide film formed during rolling, and (c) oxide coated (by oxidising iron aluminide in air). Table 4 summarizes the tensile behaviour of these specimens. The effect of surface conditions on the HE behaviour of iron aluminides can be clearly seen from this table (McKamey and Liu 1990).

It is obvious from table 4 that ductility increases upon oxide coating. Several other inferences can also be drawn from table 4 concerning chromium containing iron aluminides. The samples which were electropolished and then annealed in vacuum to minimize oxide reformation show ductilities comparable to the binary $\mathrm{Fe}_{3} \mathrm{Al}$ intermetallic in both the $\mathrm{B} 2$ and $\mathrm{DO}_{3}$ ordered conditions. There is an observable increase in ductility for chromium containing samples as compared to the base $\mathrm{Fe}_{3} \mathrm{Al}$ intermetallic

Table 3. Room temperature mechanical properties of $\mathrm{Fe}_{3} \mathrm{Al}$ and $\mathrm{Fe}_{3} \mathrm{Al}+\mathrm{Cr}$ alloys (McKamey et al 1988).

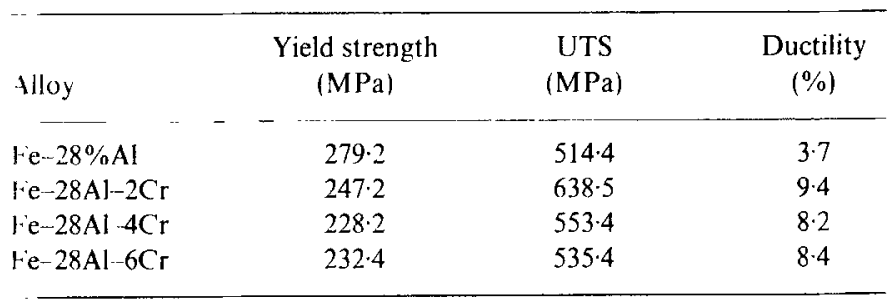

Table 4. Effect of surface condition on room temperature mechanical properties of $\mathrm{Fe}_{3} \mathrm{Al}$ dnd $\mathrm{Fe}_{3} \mathrm{Al}+\mathrm{Cr}$ in air (McKamey and Liu 1990).

\begin{tabular}{|c|c|c|c|c|c|c|c|}
\hline \multirow[b]{2}{*}{$\begin{array}{l}\text { Crystal } \\
\text { itructure }\end{array}$} & \multirow[b]{2}{*}{$\begin{array}{l}\text { Surface } \\
\text { condition }\end{array}$} & \multicolumn{3}{|c|}{$\mathrm{Fe}_{3} \mathrm{Al}(28 \mathrm{at} \% \mathrm{Al})$} & \multicolumn{3}{|c|}{$\mathrm{Fe}_{3} \mathrm{Al}-4 \mathrm{Cr}$} \\
\hline & & $\begin{array}{l}\text { Y.S. } \\
\text { (MPa) }\end{array}$ & $\begin{array}{c}\text { UTS } \\
\text { (MPa) }\end{array}$ & $\begin{array}{l}\text { Elong. } \\
(\%)\end{array}$ & $\begin{array}{l}\text { Y.S. } \\
(\mathrm{MPa})\end{array}$ & $\begin{array}{c}\text { UTS } \\
\text { (MPa) }\end{array}$ & $\begin{array}{c}\text { Elong. } \\
(\%)\end{array}$ \\
\hline \multirow[t]{2}{*}{ B.2 } & $\begin{array}{l}\text { Electro- } \\
\text { polished }\end{array}$ & 387 & 559 & $4 \cdot 1$ & 256 & 364 & $4 \cdot 0$ \\
\hline & As received & 398 & 587 & $4 \cdot 3$ & 199 & 433 & $7 \cdot 8$ \\
\hline \multirow[t]{2}{*}{$\mathrm{DO}_{3}$} & $\begin{array}{l}\text { Electro- } \\
\text { polished }\end{array}$ & 267 & 515 & $5 \cdot 4$ & 192 & 356 & $5 \cdot 8$ \\
\hline & Is received & 277 & 551 & $5 \cdot 6$ & 196 & 423 & $7 \cdot 2$ \\
\hline \multirow[t]{2}{*}{$\mathrm{DO}_{3}$} & Oxide coating & 270 & 429 & 3.6 & 236 & 483 & $8 \cdot 2$ \\
\hline & Is received & 285 & 466 & $3 \cdot 6$ & 248 & 461 & $7 \cdot 0$ \\
\hline
\end{tabular}



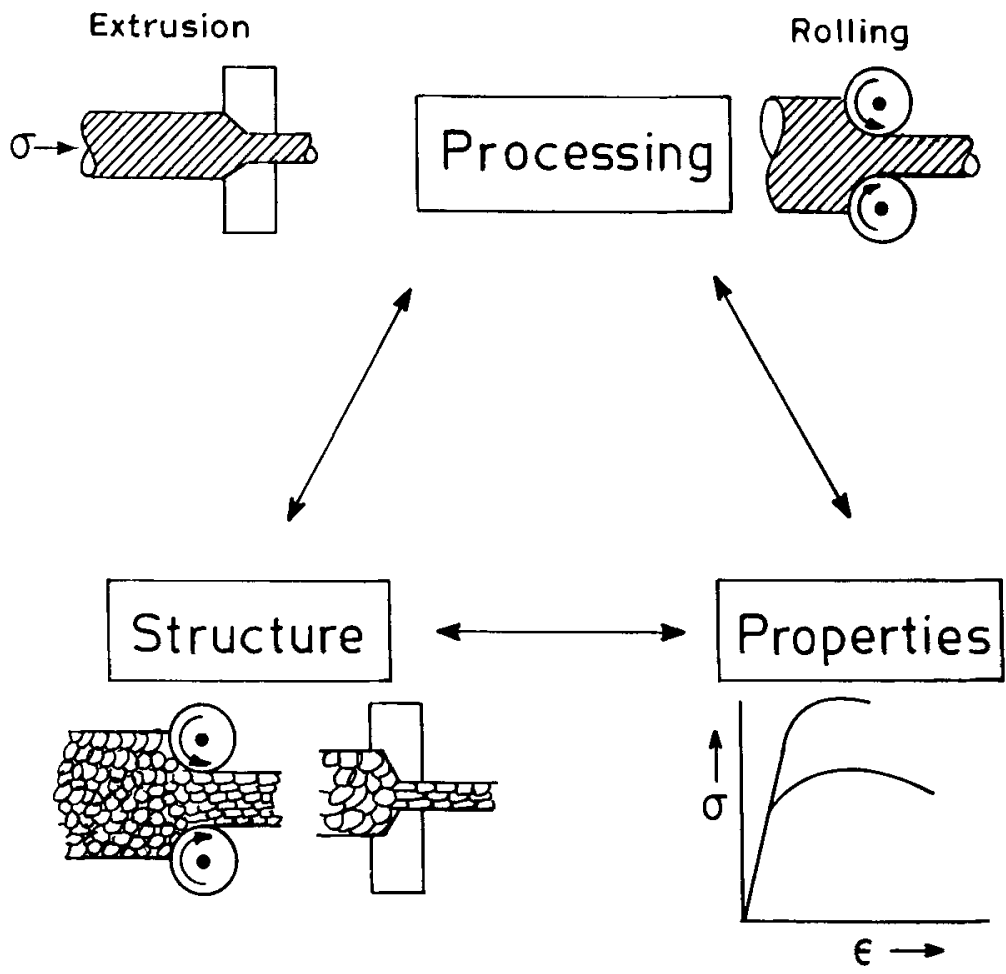

Figure 6. Correlation between processing-structure-properties.

in the as-rolled condition. Chromium containing specimens which were heat treated for $96 \mathrm{~h}$ at $500^{\circ} \mathrm{C}$ in air (to give $\mathrm{DO}_{3}$ crystal structure) show comparable ductilities, whether they were oxide coated or present in the as-rolled condition or provided a protective oxide coating. And finally, ductility of oxide coated ( $\mathrm{Cr}$ containing) specimen is higher than the electropolished specimen. These results strongly suggest that surface passive films on iron aluminides restrict hydrogen embrittlement.

\section{Alloy development philosophy}

Thermomechanical treatments (TMT) of these intermetallics are also being evaluated to understand their effects on mechanical properties. It is well known that mechanical properties can be controlled by processing, which also controls the microstructure (figure 6). For example, an iron aluminide block of composition $\mathrm{Fe}-25 \% \mathrm{Al}$ (obtained from the Defence Metallurgical Research Laboratory, Hyderabad) was homogenized at $1000^{\circ} \mathrm{C}$ for 4 days and was then rolled to $80 \%$ deformation at three different temperatures of 500,800 and $1000^{\circ} \mathrm{C}$. Figure 7 a summarizes the room temperature stress-strain behaviour after the TMTs. It can be observed that fracture (or yield) strength increases with increasing rolling temperature (Agarwal et al 1996). The fracture surface morphologies of $\mathrm{Fe}-25 \% \mathrm{Al}$ rolled at these temperatures are also presented in figures $7 \mathrm{~b}-\mathrm{d}$. There is an indication of mixed mode fracture in the sample 

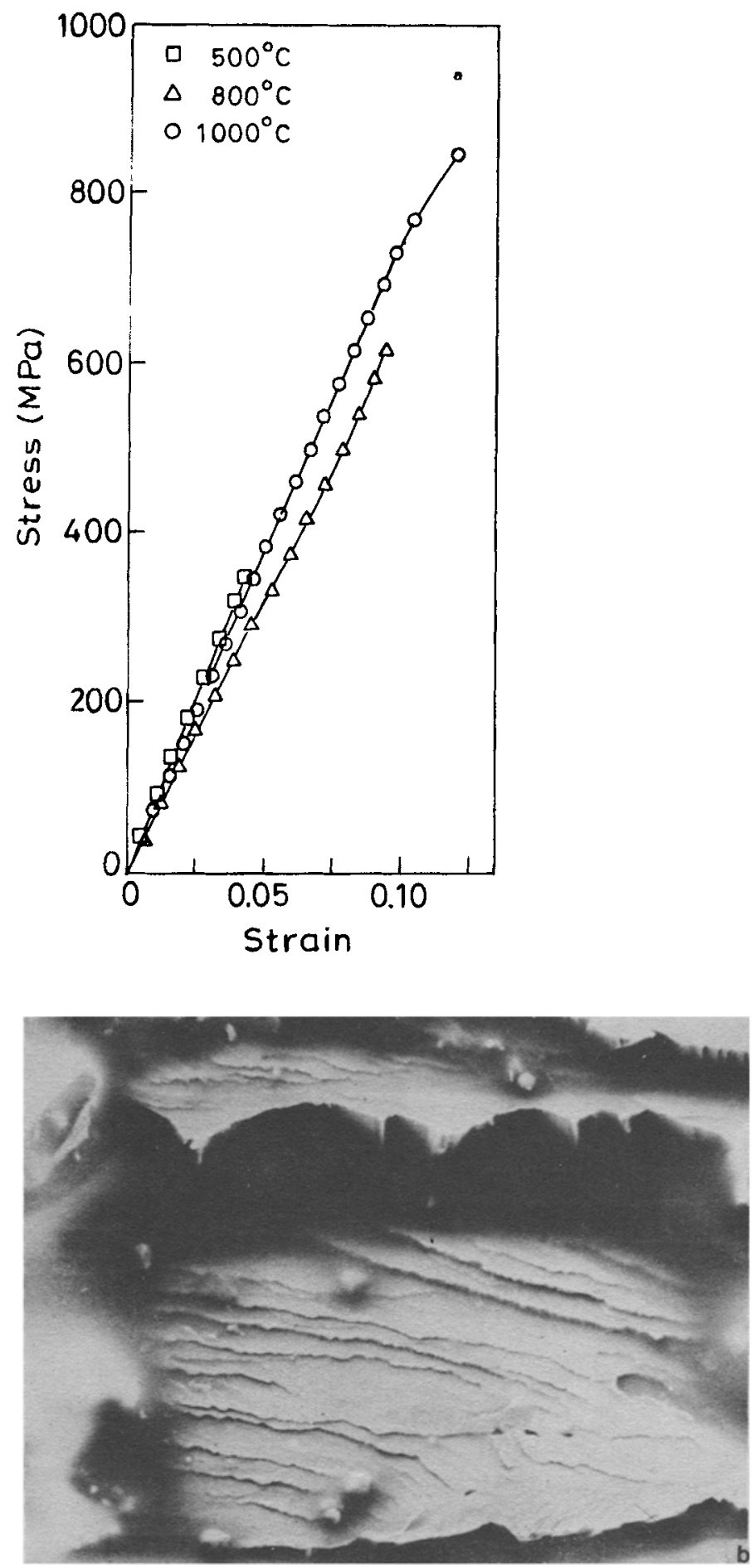

ligure 7. (a)-(b) 

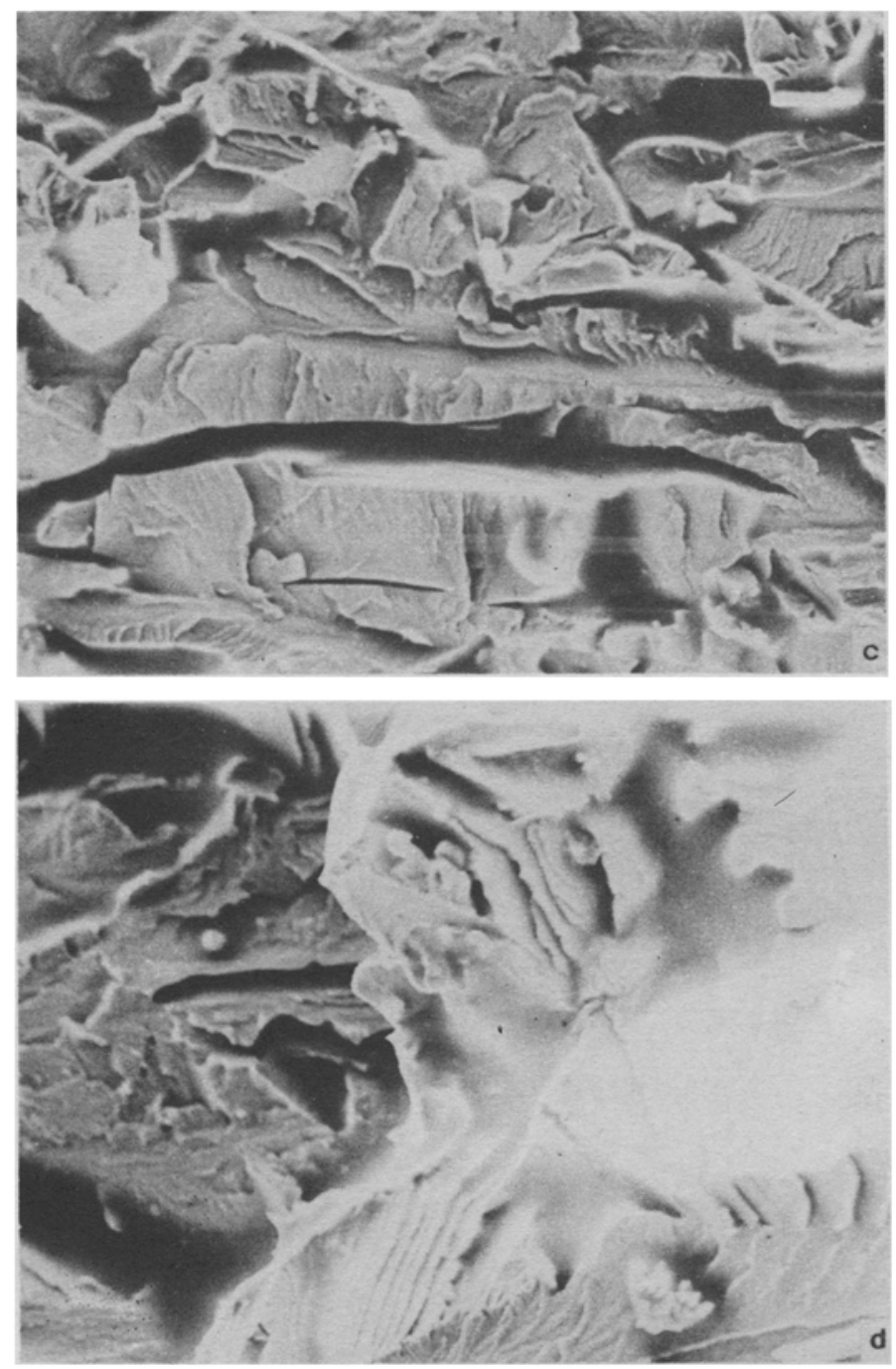

Figure 7. (a) Room temperature stress-strain behaviour of $\mathrm{Fe}-25 \% \mathrm{Al}$ after $80 \%$ rolling deformation at 500,800 and $1000^{\circ} \mathrm{C}$. Fracture morphologies for specimens rolled at (b) $500^{\circ} \mathrm{C}$. (c) $800^{\circ} \mathrm{C}$ and (d) $1000^{\circ} \mathrm{C}$ (Agarwal et al 1996).

rolled at $1000^{\circ} \mathrm{C}$. The fracture surfaces of the specimen rolled at $1000^{\circ} \mathrm{C}$ also shows both ductile and cleavage fracture features while in the specimen rolled at $500^{\circ} \mathrm{C}$, a complete cleavage type of fracture is observed. The effect of recrystallization and ordering on the room temperature tensile properties have been studied (Agarwal et al 1996).

The ongoing alloy development work at IIT Kanpur to produce ductile iron aluminides is based upon the philosophy of passivation of fresh surfaces by appropriate alloying additions thereby restricting hydrogen reduction rates and subsequent hydrogen entry into the lattice (Balasubramaniam 1996). A novel mechanism has been proposed to explain the role of passive film in restricting hydrogen embrittlement 


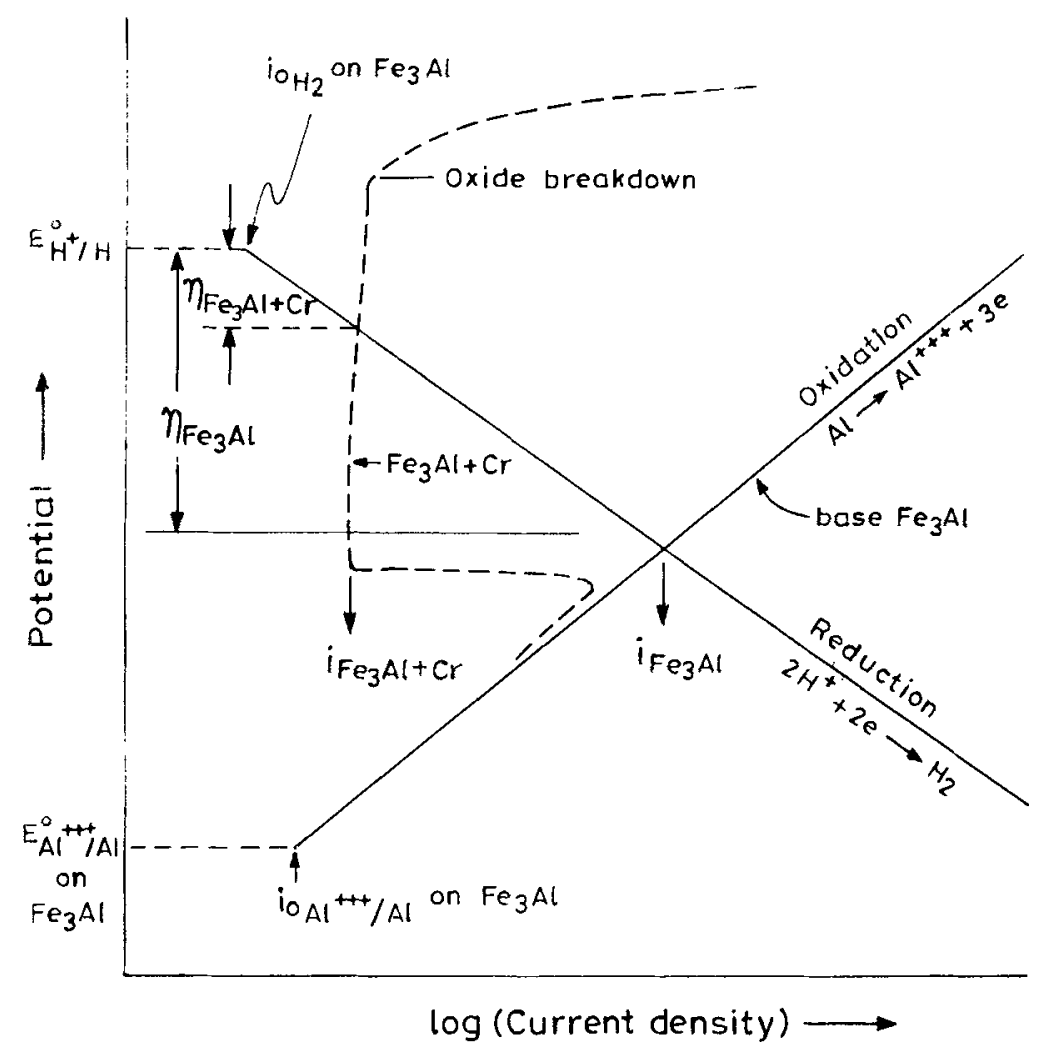

Figure 8. Schendic polarthaton diagram based on the mixed potential theory explaining the corrosion behaviour of iron aluminides (Balasubramaniam 1994).

(Balasubramantam 1996). According to this theory, addition of passivity inducing elements changes the nature of anodic polarization curve and shifts the corrosion potential into passive range as shown in the polarization diagram of figure 8 . This has also been verified experimentally (figure 9) by potentiodynamic polarization studies (Akhtar and Balasubramaniam 1996). Intermetallics of type $\mathrm{Fe}_{3} \mathrm{Al}-\mathrm{M}$ are currently being synthesized, processed and characterized at IIT Kanpur. The elements that can be added to the base $\mathrm{Fe}_{3} \mathrm{Al}$ composition should induce passivity. The effect of alloying on passivation behaviour of iron is known (Tomashov and Chernova 1967). These are $\mathrm{V}, \mathrm{Nb}, \mathrm{Ti}, \mathrm{Ta}, \mathrm{W}, \mathrm{Mo}, \mathrm{Si}, \mathrm{Ni}$ and $\mathrm{Cr}$. These intermetallics are under development.

\section{Conclusion}

The role of surface passive films on the hydrogen embrittement behaviour of iron dluminides has been reviewed. The development of ductile $\mathrm{Fe}_{3} \mathrm{Al}-\mathrm{M}$ intermetallics based on the philosophy of passivation is presented. Hydrogen entry can be restricted by passivation of these alloys. Addition of suitable alloying elements (which passivate $\mathrm{Fe}_{3} \mathrm{Al}$ ) and thermomechanical treatments would yield ductile $\mathrm{Fe}_{3} \mathrm{Al}$ intermetallics for applications as useful high temperature structure materials in the near future. 


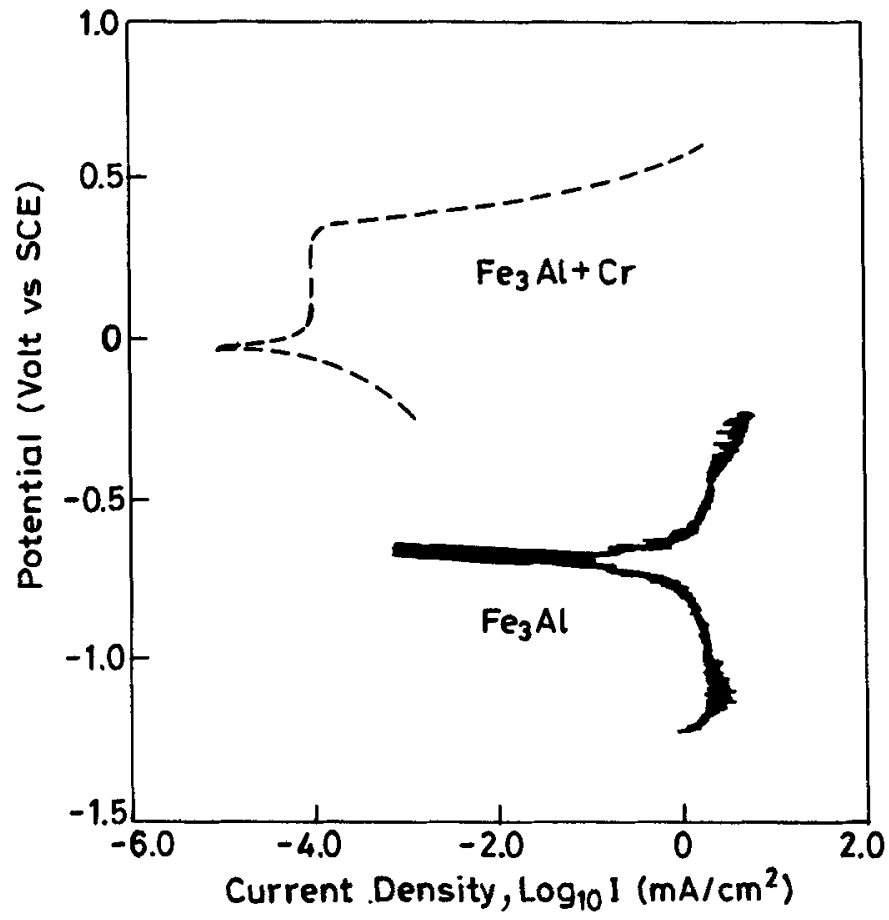

Figure 9. Potentiodynamic polarization curves of $\mathrm{Fe}_{3} \mathrm{Al}$ and $\mathrm{Fe} \mathrm{e}_{3} \mathrm{Al}+\mathrm{Cr}$ in $\mathrm{pH}=4 \mathrm{H}_{2} \mathrm{SO}_{4}$ solution containing $200 \mathrm{ppm} \mathrm{Cl}^{-}$(Akhtar and Balasubramaniam 1996).

\section{References}

Agarwal A, Balasubramaniam R and Bhargava S 1996 Metall. Mater. Trans. (accepted)

Akhtar M J and Balasubramaniam R 1996 Corrosion (communicated)

Balasubramaniam R 1996 Scr. Metall. Mater. (in press)

Li J C M and Liu C T 1992 Scr. Metall. Mater. 271701

Liu C T and Kumar K S 1993 J. Metals 4538

Liu C T, McKamey C G and Lee E H 1990 Scr. Metall. Mater. 24385

Liu Y, Takasugi T, Izumi O and Yamada T 1989 Acta Metall. 37507

McKamey C G, Horton J A and Liu C T 1988 Scr. Metall. 221679

McKamey C G and Liu C T 1990 Scr. Metall. Mater. 242119

Stoloff N S and Duquette D J 1993 J. Metals 4530

Tomashov N D and Chernova G P 1967 Passivity and protection of metals against corrosion (New York:

Plenum Press) Ch. 3 pp. 67-105 